\title{
Impact of hypomineralized teeth and sociobehavioral aspects on caries development: a prospective cohort study
}

\author{
Cristiane Maria da Costa Silva ${ }^{1}$, Glaucia Maria Bovi Ambrosano², Fábio Luiz Mialhe² \\ 1Prefeitura Municipal de Poços de Caldas, Health's Secretary, Oral health coordinator, Poços de Caldas, MG, Brazil \\ ${ }^{2}$ Universidade Estadual de Campinas - UNICAMP, Piracicaba Dental School, Department of Community Dentistry, Piracicaba, SP, Brazil
}

\begin{abstract}
Aim: This prospective cohort study was to evaluate the independent and mutual effects of socioeconomic, oral health behaviors and individual clinical factors, including enamel hypomineralization, as possible risk factors for increase in caries experience in second primary molar (SPM) over a period of 2-years. Methods: Children $(n=216)$ aged 4-6 years were examined for hypomineralized second primary molar (HSPM) and dental caries in school settings and were recalled every 6 months. The caregivers filled out a semi-structured questionnaire about their socio-demographic and oral health-related behaviors. Data analysis was performed using a hierarchical model with three levels. Multiple analyses were performed at each level and variables with $p<0.20$ were tested by stepwise multiple Generalized Estimating Equation. Results: At final examination, $33.3 \%$ of the children had developed new caries lesions in SPM. The model showed that the number of years of mother's schooling and the caregiver's perception about their children's caries experience played a protective role in the incidence of dental caries. Children who had white spot lesions were more likely to develop new carious lesions in SPM. Children with HSPM showed no higher incidence of caries in their SPM than those without HSPM. Conclusions: Clinical, socioeconomic and behavioral factors impacted on caries development in primary second molars. However, further studies are required to better understand the role of HSPM in caries development in other age groups.
\end{abstract}

Keywords: dental caries; tooth hypomineralization; socioeconomic factors.

\section{Introduction}

Despite the reduction in the incidence of dental caries, it continues to be the most prevalent oral disease in childhood ${ }^{1-2}$. Concern about the high prevalence of caries in primary dentition has led the researchers around the world to conduct

Received for publication: November 09, 2015 Accepted: December 13, 2015

Correspondence to: Fábio Luiz Mialhe

Faculdade de Odontologia de Piracicaba - UNICAMP Departamento de Odontologia Social Avenida Limeira 901, Bairro Areão CEP 13414-903 - Piracicaba, SP, Brazil Phone: +55 19 21065279/Fax: +55 1921065248 E-mail: mialhe@fop.unicamp.br studies about the influence of various risk factors on the onset of disease, among which enamel hypomineralizations are outstanding ${ }^{3-4}$. In this context, second primary molars (SPM) have attracted the attention, not only because of their high risk for caries development but also because of the prevalence of idiopathic demarcated enamel hypomineralization, called hypomineralized second primary molar (HSPM) $)^{3-6}$.

Studies indicate that the microstructure of enamel hypomineralization favors the development of caries lesions due to its lower mechanical strength, which often shows structural losses and provides retention niches for dental biofilm ${ }^{7-8}$. Another factor that could contribute to the higher caries experience among children 
with hypomineralized teeth is the great and repeated need for restorative treatment of the affected teeth, as a result of the low mechanical resistance of the affected enamel ${ }^{7,9-10}$.

However, the results of studies among children with enamel hypomineralizations may be controversial. While some studies point towards a supposed influence of enamel defects in the development of carious lesions, others have found no associations between hypomineralized enamel and dental caries $^{4,6,10-12}$. This demonstrates the need to evaluate the influence of other variables, such as socioeconomic status and oral health behavior of children on posteruptive behavior of these enamel hypomineralizations and their influence on the development of dental caries in the affected teeth. In addition, studies have shown that mothers' untreated caries almost doubled the odds of children's untreated caries, showing the multiple determinants involved in the disease ${ }^{13}$. Hence, the evidence of the risk factors involved in the development of dental caries may only be obtained from cohort studies.

The aim of this study was to evaluate the plausibility of environmental, behavioral and clinical factors, especially the presence of HSPM, as potential risk factors for the development of new caries lesions in SPM tooth surfaces over a period of 2-years.

\section{Material and methods}

Approval for this assessment was obtained from the Ethics Committee of the Piracicaba Dental School, São Paulo, Brazil (Protocol 037/2010).

A population-based study was conducted, in which all children from 4 - 6 years $(n=230)$ of age, resident in the rural and urban zones of Botelhos, Minas Gerais, Brazil, were invited to participate. The study was conducted from 2010 to 2012. The city has slightly over 15.000 inhabitants and has a Human Development Index of 0.7, which is considered high and the municipal water system adjusts the level of fluoride to $0.7 \mathrm{ppmF}$.

At baseline (2010), 216 children aged 4-to-6-years-old were examined (93.9\% of all eligible children). The exam was carried out in the school environment by the first author. The training and calibration process included theoretical information, preliminary diagnostic training with photographs and clinical evaluation. To determine intraexaminer agreement, about $10 \%$ of the examined children were randomly selected and re-examined in the field work, on a separate occasion, after a $24 \mathrm{~h}$ interval. The kappa values for intra-examiner reliability with regard to the presence of dental caries and HSPM were 0.92, and 0.94, respectively.

Before the examination, the participating children received a toothbrush and fluoridated toothpaste (1.100 ppmF) to brush their teeth. Children were recalled and examined every 6 months from 2010 to 2012. The follow-up exams were carried out under the same conditions as those at baseline.

The prevalence of dental caries was assessed by using the dmft index (number of decayed, missing and filled primary teeth) in accordance with the World Health Organization, with a mirror and dental probe ${ }^{14}$. Dental caries on SPM was assessed by the dmft index ${ }^{14}$. A carious lesion was recorded in a SPM, when the surface had an unmistakable cavity, undermined enamel, or a detectably softened floor or wall on their coronal surface. No radiographs were taken. The presence of white spot lesions on SPM surfaces was recorded.

HSPM was diagnosed when the child had one or more SPM with demarcated opacities or post-eruptive break-down of the hypomineralized enamel or/and atypical restorations according to the EAPD criteria, which have already been presented in other studies conducted by the authors ${ }^{9,11,15}$. Demarcated enamel opacities were differentiated from initial caries lesions (white spot), according to their location in the teeth. White spot carious lesions present an enamel surface with a whitish/yellowish opaque coloration, occur under dental plaque, are located adjacent to the gingival margin and extend along the buccal or lingual surfaces and/or in pits or fissures ${ }^{9,14}$. In contrast, demarcated enamel opacities have no preferential location on the tooth ${ }^{9}$. Clinically detectable dental plaque on the buccal surfaces of the anterior primary teeth was recorded.

The caregivers filled out a semi-structured questionnaire about their socio-demographic and oral health-related behaviors, considered independent variables that could be related to their children's oral health status. The theoretical model for this study comprised three levels, based on a hierarchical approach ${ }^{16}$.

Level 1 of the model comprised socioeconomic and demographic variables concerning the child's environment at baseline. The lowest level of parents' education represents functional illiteracy in Brazil ${ }^{16}$. The head of the household's occupation was established by the question: what is the head of the household's occupation? Occupation was classified in accordance with the Brazilian Occupation Classification (BCO), regrouped into 2 categories: unskilled labor (for example: sales persons at stores and markets, maintenance workers, persons working in agricultural, forestry, hunting and fishing activities) and workers at technical or higher levels (science and art professionals, medium level technicians, workers at administrative level) ${ }^{17}$.

Level 2 of the model included factors involved in children's oral health-related behaviors (frequency of tooth brushing; mother's helping the child with tooth brushing; frequency of consuming sweets by children; dental care visits in children's life; mothers' perception of dental caries in their children through question "Do you think your child has had cavities?").

Level 3 involved the children's clinical variables at baseline (caries experience measured by dmft index; presence of visible plaque; presence of HSPM; presence of white spot lesions on SPM).

At follow-ups, a calibrated dentist (CMCS) evaluated the children for increment of dental caries in SPM allowing direct comparisons to be made after a period of two years.

The number of new decayed (d), filled (f) and missing (m) surfaces due to dental caries were calculated for the sample and was dichotomized into yes - new lesion of caries and no - no new caries lesions ${ }^{14}$. 
Analysis was performed using the Generalized Estimating Equation (GEE) to evaluate the possible risk factors for increase in caries experience. The hierarchical model was used, with the demographic and socioeconomic variables considered as the first level, behavioral variables the second level and clinical variables the third level. Multiple analyses were performed at each level and the variables that presented values of $p<0.25$ were tested in the hierarchical model for stepwise multiple GEE, selecting those with values of $p \leq 0.05$. All analyses were performed with the statistical software program SAS (SAS version 9.2). Explanatory variables were selected for the final models only if they had a $p$-value of $<0.05$ after adjustment for variables from the same or previous levels of determinants.

\section{Results}

In this study the data from 216 children were initially used (47.22\% boys; mean age $5.22, \mathrm{SD} \pm 0.86$ ). The response rates at each of the 6-month follow-ups were 204 (94.44\%), $196(90.74 \%), 186(86.1 \%)$ and $174(80.55 \%)$, respectively. The dropout rate was mainly due to participants who moved from the city.

At baseline, the mean dmft index of the children was 2.45 and 81 children (37.5\%) presented dental caries in one of their SPM according to WHO criteria. At tooth level, among all 864 SPM included in the analysis, $22.15 \%$ corresponded to caries experience in children at age 4 (median dfs $=0.20$ per tooth), $26.36 \%$ at age 5 (median dfs $=0.26$ per tooth), $24.0 \%$ at age 6 (median DFS $=0.24$ per tooth).

In relation to the HSPM, the prevalence of children with HSPM was $22.2 \%(48 / 216)$ at baseline and it was observed that children with HSPM had more dental caries lesions in their SPM than those without HSPM ( $\chi^{2}$ test, $p<0.0001$; $\mathrm{OR}=2.57$, IC [1.20-5.53]). At tooth level, the prevalence was of $7.4 \%(64 / 864)$, with a total of 76 surfaces with this enamel defect. No statistical differences were found in the presence of HSPM between the mandible and maxilla, or between the left and right sides. Demarcated enamel opacities (89\%) were the most frequently scored characteristics of HSPM, followed by atypical restorations and post-eruptive enamel loss. In relation to the HSPM color, $4.7 \%$ were brown, 35.9 were yellow and 59.4 were white.

At the final examination after 2 years, 31.8\% (14/44) of children initially aged 4 years; $36.3 \%(20 / 55)$ at 5 years and $32.0 \%(24 / 75)$ at 6 years respectively, developed news caries lesions in their SPM. The caries increment was mainly due to the incidence of decayed surfaces (92\%), followed by fillings (7\%) and extracted teeth (1\%). Among the 48 children presenting HSPM at baseline, only 2 presented caries increment in their HSPM after 2 years.

\section{Multivariable Analyses at Each Level}

The analyses were performed at subject-level. Income levels were low for most children's families, with 36\% (89/ 174) of them living on an income of up to 1 minimum monthly wage. The majority of parents also had low educational levels, with only $22.1 \%$ (38/172) of the fathers and $28.1 \%(52 / 185)$ of mothers completed more than 8 years of formal education. For level 1 (socio-demographic factors), the mothers' higher educational level was a protective factor for caries incidence in SPM (Table 1).

For level 2, the mothers' perception of the presence or absence of dental caries in their children was a protective factor for incidence of new caries lesions in SPM (Table 2). As regards the variables at level 3, only the variable presence of white spot lesions at baseline was associated with increased risk of caries development in SPM after two years (Table 3).

\section{Stepwise Multivariable Analysis}

The multivariable stepwise GEE analysis generated models 1 through 3. The models (model 1-3) are shown in Table 4. The final model (Model 3) showed that a high level of schooling and the caregiver's positive perception of child's dental caries, played a protective role in the incidence of dental caries. Moreover, children with white spot lesions (WSL) at baseline were more likely to develop new dental caries lesions in their SPM.

\section{Discussion}

Dental caries is a chronic childhood disease that can cause pain and impact the quality of life of younger children, affecting mainly the second primary molars ${ }^{1,3-6}$. Thus, it is important that health professionals know the risk factors associated with the development of the disease in these teeth, in order to implement measures to maintain and promote the oral health of this population. The disease has a multifactorial etiology including social, economic, behavioral and oral variables that must be accounted for in the process of diagnosis and treatment.

In the present study, instead of using socioeconomic status as a single index for evaluating the impact of social determinants on caries incidence, a set of socioenvironmental variables was included, comprising family environment (parents' education and family income), number of children, access to fluoridated community water and rural or urban residence, which could have an influence on caries development ${ }^{2}$. We observed that children whose mothers had a higher level of schooling and had the perception of the presence of dental caries in their children were less likely to develop new caries lesions in their SPM after two years. Mothers are usually more directly involved in child feeding than fathers in the first five years of life and the maternal educational level has been identified as a factor associated with cariogenic feeding practices ${ }^{18-19}$. Studies have indicated that the children whose mothers had a higher socioeconomic level, brushed their teeth more frequently, consumed fewer cariogenic foods, visited the dentist more frequently showed lower prevalence of caries in comparison with children whose mothers had a lower educational level ${ }^{2,20-21}$. These behaviors are related to caries experience: the more frequently they are performed, the lower the children's DMFS index ${ }^{19,21}$.

Likewise, the mothers' perception of the presence of 
Table 1. Association between socioeconomic and demographic factors and incidence of dental caries.

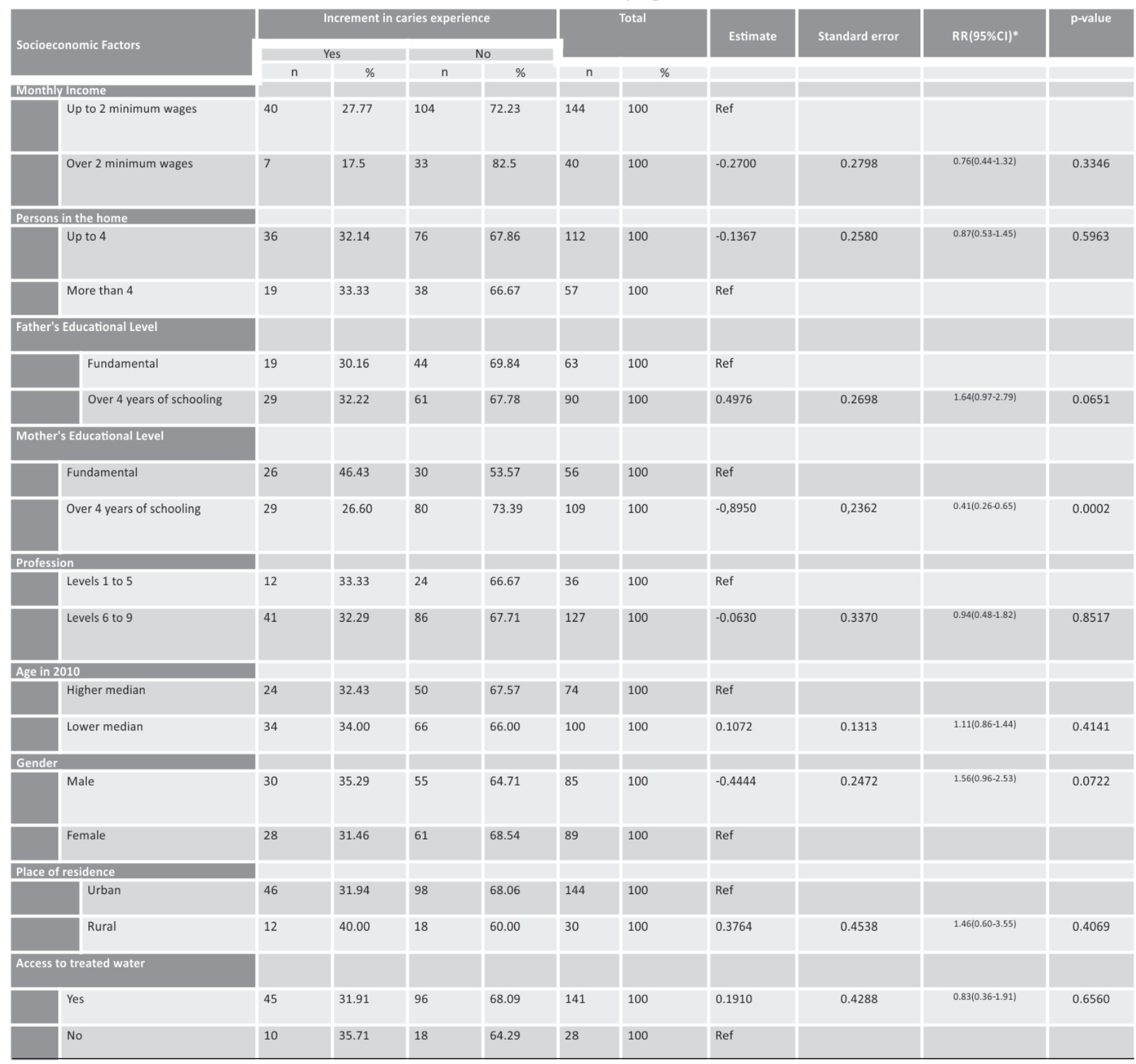

"RR = Relative Risk; $\mathrm{Cl}=$ Confidence Interval.

caries in their children was inversely associated with dental caries increment in SPM over two years. A hypothesis is that the mother's perception of oral disease in their children may have influenced their attitudes regarding the need for greater oral health care attention on their kids. To our knowledge, this is the first longitudinal study that verified that perception of parents about the oral condition of their children might be a factor of protection for caries increment in their SPM.

In relation to clinical variables, the presence of white spot lesions at baseline was a risk factor associated with caries development in SPM in children 4-6 years old over the two years follow-up. White spot lesions are considered a high risk for caries since the precavitated lesions are indicative of caries activity ${ }^{22}$ and the findings found in the present study reinforce the evidence in the literature of the importance of past caries experience as an important risk predictor for disease.
Although enamel hypomineralization is a phenomenon described in other studies, there are still few studies investigating the prevalence of HSPM in populations ${ }^{6,23-24}$. The results of the present investigation demonstrated a prevalence of $22.2 \%$, which was higher than values found by other authors like Elfrink et al. ${ }^{23}$, who found a prevalence rate of $4.9 \%$ at child level in a sample of 386 Dutch 5-yearold children. Among Iraqi children, a prevalence of $6.6 \%$ was found in a sample of 809 children aged 7- to 9 years old $^{6}$. Mittal and Sharma found an overall prevalence of 5.6 $\%$ in a sample of 978, 6-8-year-old school children in in Gautam Budh Nagar, Uttar Pradesh, India ${ }^{24}$. Therefore, differences in the age of the sample, contextual and environmental variables could impact on the prevalence of disease.

Associations between HSPM and dental caries experience 
Table 2. Association between children's and parent's oral health-related behaviors and incidence of dental caries.

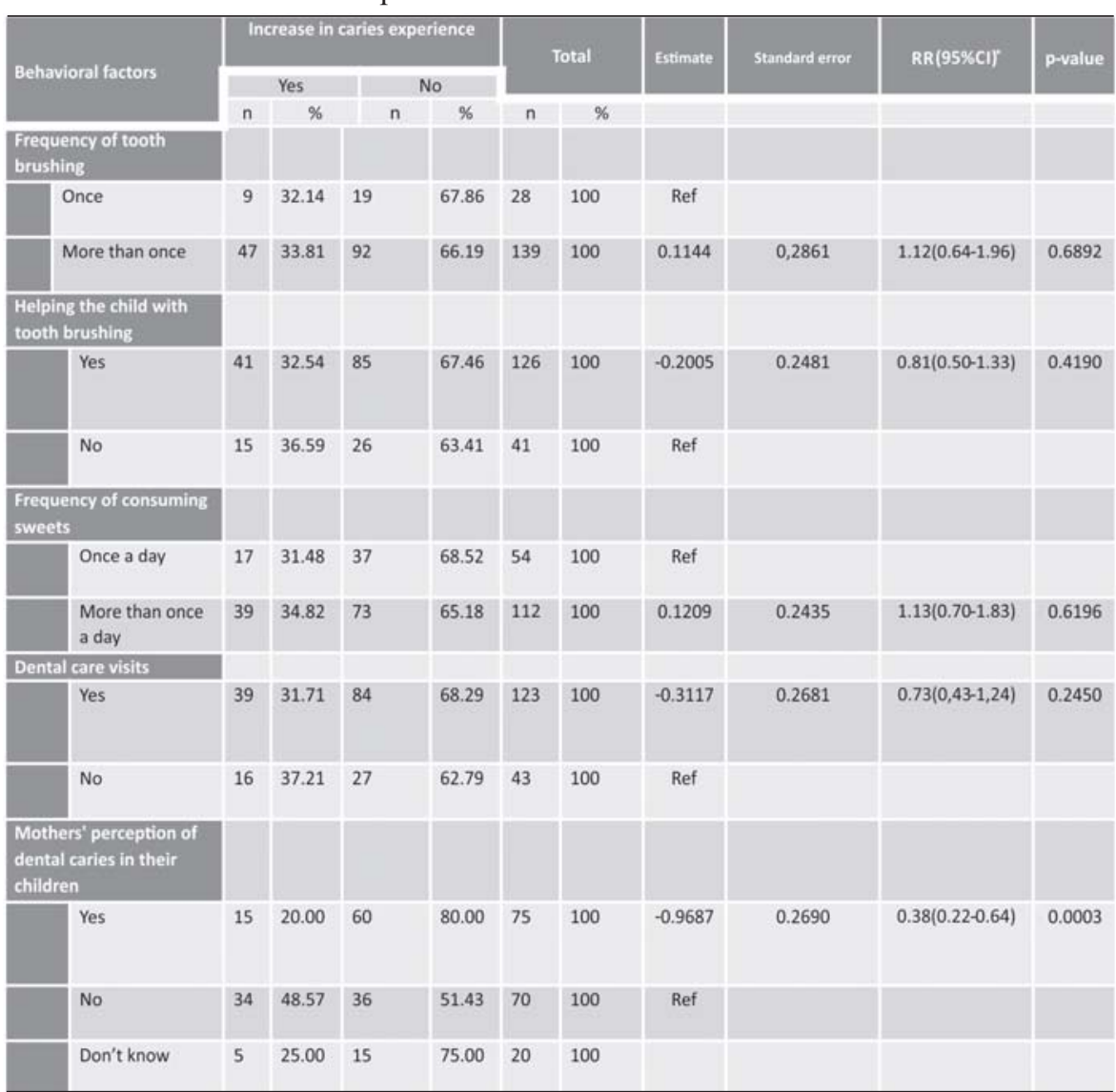

${ }^{*} \mathrm{RR}=$ Relative Risk; $\mathrm{Cl}=$ Confidence Interval

Table 3. Association between the children's clinical variables and incidence of dental caries.

\begin{tabular}{|c|c|c|c|c|c|c|c|c|c|c|}
\hline \multirow{3}{*}{ Clinical Factors } & \multicolumn{4}{|c|}{ Increment in caries experience } & \multirow{2}{*}{\multicolumn{2}{|c|}{ Total }} & \multirow{3}{*}{ Estimate } & \multirow{3}{*}{$\begin{array}{c}\text { Standard } \\
\text { error }\end{array}$} & \multirow{3}{*}{$\operatorname{RR}^{*}(95 \% \mathrm{C})$} & \multirow{3}{*}{ p-value } \\
\hline & \multicolumn{2}{|c|}{ Yes } & \multicolumn{2}{|c|}{ No } & & & & & & \\
\hline & $\mathrm{n}$ & $\%$ & $\mathrm{n}$ & $\%$ & $\mathrm{n}$ & $\%$ & & & & \\
\hline \multicolumn{11}{|l|}{ Caries in baseline } \\
\hline Yes & 33 & 47.14 & 37 & 54.86 & 70 & 100 & 0.3459 & 0.2976 & $1.41(0.79-2.53)$ & 0.2451 \\
\hline No & 21 & 20.19 & 83 & 78.81 & 104 & 100 & Ref & & & \\
\hline \multicolumn{11}{|c|}{ Presence visible plaque } \\
\hline Yes & 36 & 47.37 & 40 & 52.63 & 76 & 100 & 0.2637 & 0.2395 & $1.30(0.81-2.08)$ & 0.2708 \\
\hline No & 22 & 22.45 & 76 & 77.55 & 98 & 100 & Ref & & & \\
\hline \multicolumn{11}{|c|}{ Presence of HSPM } \\
\hline \begin{tabular}{|l|l} 
Yes \\
\end{tabular} & 16 & 47.06 & 18 & 52.94 & 34 & 100 & 0.1906 & 0.2203 & $1.21(0.78-1.86)$ & 0.3868 \\
\hline No & 42 & 30.00 & 98 & 70.00 & 140 & 100 & Ref & & & \\
\hline \multicolumn{11}{|c|}{ Presence of WSL } \\
\hline Yes & 44 & 50.57 & 43 & 49.43 & 87 & 100 & 0.7427 & 0.3716 & $2.10(1.01-4.35)$ & 0.0456 \\
\hline No & 14 & 16.09 & 73 & 83.91 & 87 & 100 & Ref & & & \\
\hline
\end{tabular}

${ }^{1}$ HSPM=Hypomineralised Second Primary; ${ }^{2}$ WSL=White Spot Lesion. 
Table 4. Risk factors associated with incidence of dental caries analyzed by Generalized Estimating Equation.

\begin{tabular}{|c|c|c|c|c|c|c|}
\hline Variables & Model 1 & & Model 2 & & Model 3 & \\
\hline & RR (CI95\%) & p-value & RR (CI95\%) & p-value & RR (CI95\%) & p-value \\
\hline \multicolumn{7}{|l|}{ Level 1} \\
\hline \multicolumn{7}{|l|}{$\begin{array}{l}\text { Mother's Educational } \\
\text { Level }\end{array}$} \\
\hline Fundamental & Ref & & Ref & & Ref & \\
\hline $\begin{array}{l}\text { Over } 4 \text { years of } \\
\text { schooling }\end{array}$ & $0.41(0.26-0.65)$ & 0.0002 & $0.37(0.22-0.62)$ & 0.0001 & $0.39(0.24-0.64)$ & 0.0003 \\
\hline \multicolumn{7}{|l|}{ Level 2} \\
\hline \multicolumn{7}{|l|}{$\begin{array}{l}\text { Does your child have } \\
\text { caries? }\end{array}$} \\
\hline yes & & & $0.47(0.29-0.78)$ & 0.0030 & $0.59(0.35-0.99)$ & 0.0490 \\
\hline no & & & Ref & & Ref & \\
\hline \multicolumn{7}{|l|}{ Don't know } \\
\hline \multicolumn{7}{|l|}{ Level 3} \\
\hline \multicolumn{7}{|l|}{$\begin{array}{l}\text { Presence of white spot } \\
\text { lesion }\end{array}$} \\
\hline Yes & & & & & $1.84(1.06-3.17)$ & 0.0292 \\
\hline No & & & & & Ref & \\
\hline
\end{tabular}

${ }^{*} \mathrm{RR}=$ Relative Risk; $\mathrm{Cl}=$ Confidence Interval.

have been observed in cross-sectional studies, in which children with HSPM have greater caries experience in their $\mathrm{SPM}^{4,6}$. Information from the baseline of the present study showed the same tendency, i.e. children with HSPM had 2.57 times greater chance of showing caries lesions in their SPM, indicating that HSPM could be considered an important indicator of risk for caries in SPM.

On the other hand, when we observed the outcomes of the prospective evaluation of these children, it was verified that enamel hypomineralization was not a risk factor for the development of new carious lesions in SPM. Although other studies have observed that enamel defects were predictors of caries development in primary dentition ${ }^{25-26}$, direct comparisons should be made with caution, due to various reasons.

Firstly, the age of sample and the follow up varies across the studies, for example, from 12 to 36 months of age ${ }^{25}$; ages 5 to $9^{26}$ and from birth to 54 months ${ }^{27}$ which could interfere in the risk of caries development. We suppose that there is a time-dependency ratio between enamel hypomineralization and dental caries. HSPM may have an early influence on dental caries, but the risk effect may not continue to drive subjects to an increased risk for caries many years after tooth eruption ${ }^{23}$. In the newly erupted teeth, enamel hypomineralization is more susceptible to the development of caries due to greater enamel immaturity ${ }^{9}$. Moreover, in the early childhood, parents have more difficulties to brushing their children's teeth, which certainly interferes in the amount of biofilm ${ }^{8}$. This fact suggests that further studies should be conducted in populations of a lower age than that of the present sample, preferably in subjects in whom the SPM have erupted recently.

Secondly, the criteria utilized to diagnose enamel defects differ among studies as to the number of teeth examined for defects and caries development ${ }^{25-27}$. In our study, only the SPM were examined for enamel defects, because our objective was to investigate what was the impact of an enamel defect on caries development in those teeth, not in others in oral cavity, as observed in other studies. This methodological approach could impact on the probability of associations between HSPM and caries.

Thirdly, the structure and color of enamel defect could interfere in the risk of developing caries ${ }^{25,28}$. Opacity plus hypoplasia was most significantly associated with caries than diffuse opacity alone ${ }^{25}$. Moreover, Elfrind et al. ${ }^{28}$ found that the mineral density in white opacities was not different from that in the enamel of sound molars, but deciduous molar hypomineralization opacities with yellow or brown color had a $20-22 \%$ lower mineral density compared with sound molars. In the present study, among the 48 children presenting HSPM at baseline, only 2 children presented caries increment in their HSPM after 2 years: one of them presented 4 brown opacities at baseline and the other presented one yellow opacity. Costa-Silva et al. observed in permanent molars that brown and yellow opacities were at higher risk for posteruptive enamel breakdown and caries ${ }^{15}$. Furthermore, the color of opacity could also be a factor that contributes to the development or progression of caries in SPM.

We agree with Elfrink et al. that there is a need for standardized studies on $\mathrm{HSPM}^{29}$, however, to our knowledge, this is the first prospective study to evaluate the relationship between HSPM and caries increment in SPM, using the diagnostic criteria proposed by the EAPD. Therefore, further studies are required to better understand the role of HSPM in caries development, including studies of longer duration, with larger and diverse samples, and in populations with diversified level of caries experience, in order to enable the clarification of the time-dependent relationship between HSPM, covariables and caries in primary dentition ${ }^{29}$.

\section{Acknowledgements}

Grant \# 2010/13187-3, São Paulo Research Foundation (FAPESP). 


\section{References}

1. Casamassimo PS, Thikkurissy S, Edelstein BL, Maiorini E. Beyond the $\mathrm{dmft}$ : The human and economic cost of early childhood caries. JAm Dent Assoc. 2009; 140: 650-7.

2. Li Y, Zhang YE, Yang R, Zhang Q, Zou J, Kang D. Associations of social and behavioral factors with early childhood caries in Xiamen city in China. Int J Paediatr Dent. 2011; 21: 103-11.

3. Elfrink MEC, Veerkamp JSJ, Kalsbeek $\mathrm{H}$ : Caries pattern in primary molars in Dutch 5-year-old children. Eur Arch Paediatr Dent. 2006; 7: 236-40.

4. Elfrink ME, Schuller AA, Veerkamp JS, Poorterman JH, Moll HA, ten Cate $B J$. Factors increasing the caries risk of second primary molars in 5year-old Dutch children. Int J Paediatr Dent. 2010; 20: 151-7.

5. Elfrink MEC, ten Cate JM, Jaddoe VWV, Hofman A, Moll HA, Veerkamp JSJ. Deciduous molar hypomineralization and molar incisor hypomineralization. J Dent Res. 2012; 9: 551.

6. Ghanim A, Manton D, Mariño R, Morgan M, Bailey D. Prevalence of demarcated hypomineralization defects in second primary molars in Iraqi children. Int J Paediatr Dent. 2013; 23: 1-8.

7. Mahoney EK, Rohanizadeh R, Imail FSM, Kilpatrick NM, Swain MV. Mechanical properties and microstructure of hypomineralised enamel of permanent teeth. Biomaterials 2004; 25: 5091-100.

8. Seow WK, Clifford H, Battistutta D, Morawska A, Holcombe T. Casecontrol study of early childhood caries in Australia. Caries Res. 2009; 43:25-35.

9. Weerheijm KL, Duggal M, Mejàre I, Papagiannoulis L, Koch G, Martens LC, et al. Judgement criteria for molar-incisor hypomineralization $(\mathrm{MIH})$ in epidemiologic studies: a summary of the European meeting on $\mathrm{MIH}$ held in Athens, 2003. Eur J Paediatr Dent. 2003; 4: 110-3.

10. Leppäniemi A, Lukinmaa PL, Alaluusua S. Nonfluoride hypomineralizations in the permanent first molars and their impact on the treatment need. Caries Res. 2001; 35: 36-40.

11. da Costa-Silva CM, Jeremias F, de Souza JF, Cordeiro R de C, SantosPinto L, ZuanonAC. Molar incisor hypomineralization: prevalence, severity and clinical consequences in Brazilian children. Int J Paediatr Dent. 2010; 20: 426-34 .

12. Heitmüller D, Thiering E, Hoffmann U, Heinrich J, Manton D, Kühnisch et al; GINIplus Study Group. Is there a positive relationship between molar incisor hypomineralization s and the presence of dental caries? Int J Paediatr Dent. 2013; 23: 116-24.

13. Weintraub JA, Prakash P, Shain SG, Laccabue M, Gansky SA. Mothers' caries increases odds of children's caries. J Dent Res. 2010; 89: 954-8.

14. World Health Organization. Oral health surveys basic methods. 4th ed. Geneva: WHO 1997. p. 36-44.

15. Da Costa-Silva CM, Ambrosano GM, Jeremias F, De Souza JF, Mialhe FL. Increase in severity of molar-incisor hypomineralization and its relationship with the colour of enamel opacity: a prospective cohort study. Int J Paediatr Dent. 2011; 21: 333-41.

16. Victora CG, Huttly SR, Fuchs SC, Olinto MT. The role of conceptual frameworks in epidemiological analysis: a hierarchical approach. Int J Epidemiol. 1997; 26: 224-7.

17. Brasil. Brazilian Ministry of Labor and Employment. Brazilian Classification of Occupations. Brasília; 2002. Portuguese.

18. Saldiva SR, Venancio SI, de Santana AC, da Silva Castro AL, Escuder MM, Giugliani ER. The consumption of unhealthy foods by Brazilian children is influenced by their mother's educational level. Nutr J. 2014; 13: 1-8.

19. Feldens CA, Kramer PF, Sequeira MC, Rodrigues PH, Vitolo MR. Maternal education is an independent determinant of cariogenic feeding practices in the first year of life. Eur Arch Paediatr Dent. 2012; 13: 70-5.

20. Camargo MB, Barros AJ, Frazão P, Matijasevich A, Santos IS, Peres $M A$, et al. Predictors of dental visits for routine check-ups and for the resolution of problems among preschool children. Rev Saude Publica 2012; 46: 87-97.
21. Castilho AR, Mialhe FL, Barbosa T de S, Puppin-Rontani RM. Influence of family environment on children's oral health: a systematic review. J Pediatr. 2013; 89: 116-23.

22. American Academy of Pediatric Dentistry. Guideline on caries-risk assessment and management for infants, children, and adolescents. Pediatr Dent. 2013 ;35: E157-64.

23. Elfrink MEC, Schuller AA, Weerheijm KL, Veerkamp JSJ. Hypomineralised second primary molars: prevalence data in Dutch 5year-olds. Caries Res. 2008; 42: 282-5.

24. Mittal N, Sharma BB. Hypomineralised second primary molars: prevalence, defect characteristics and possible association with Molar Incisor Hypomineralization in Indian children. Eur Arch Paediatr Dent. 2015; $16: 441-7$.

25. Oliveira AFB, Chaves AMB, RosenblatA. The influence of enamel defects on the development of early childhood caries in a population with socioeconomic status: a longitudinal study. Caries Res. 2006; 40: 296302.

26. Hong L, Levy SM, Warren JJ, Broffitt B. Association between enamel hypoplasia and dental caries in primary second molars: a cohort study. Caries Res. 2009; 43:345-53.

27. Targino AG, Rosenblatt A, Oliveira AF, Chaves AM, Santos VE. The relationship of enamel defects and caries: a cohort study. Oral Dis. 2011; 17: 420-6.

28. Elfrink ME, ten Cate JM, van Ruijven LJ, Veerkamp JS. Mineral content in teeth with deciduous molar hypomineralization (DMH).J Dent. 2013; 41: 974-8.

29. Elfrink ME, Ghanim A, Manton DJ, Weerheijm KL. Standardised studies on Molar Incisor Hypomineralization (MIH) and Hypomineralised Second Primary Molars (HSPM): a need. Eur Arch Paediatr Dent. 2015; 16 : 247-55. 